\title{
PREVALENCE OF SINGLE UMBILICAL ARTERY AND ASSOCIATED CONGENITAL ANOMALIES - A FOETAL STUDY
}

\author{
Sreekumar R', Savithri Krishnan ${ }^{2}$
}

${ }^{1}$ Assistant Professor, Department of Anatomy, Government Medical College, Trivandrum, Kerala.

2Professor, Department of Anatomy, Government Medical College, Kollam, Kerala.

ABSTRACT
BACKGROUND
Congenital anomalies form one of the leading causes of foetal loss and infant mortality. The survival of the foetus during the
gestational period depends upon the state of the umbilical cord and the vascularity that it provides. Compromise of the foetal blood
flow through the blood vessels can have serious effects on the health of the foetus and the new born. Various congenital anomalies
are present in relation to the single umbilical artery. Since umbilical cord anomalies can be diagnosed prenatally, the potential to
improve foetal survival is more.
The aim of the present study was to find out the pattern of congenital anomalies and its association with single umbilical artery.

\section{MATERIALS AND METHODS}

A total of 110 foetal autopsy cases were considered for this study. Descriptive analytical methods were used to assess the patterns of intra-group findings in both foetus and umbilical cord.

\section{RESULTS}

The overall prevalence of congenital malformation obtained in this study was $48.18 \%$ and of these $47.17 \%$ were with multiple congenital anomalies and $52.83 \%$ with single anomaly. There were 6 single umbilical artery cases, which constituted a prevalence of 5.45\%. Of the 6 single umbilical artery cases, 4 were associated with congenital anomalies (66.67\%). Vertebral anomalies were the most common congenital anomalies followed by meningomyelocele and webbed neck.

\section{CONCLUSION}

Since umbilical cord lesions can be diagnosed prenatally, awareness and detection of the conditions in the antenatal period will improve foetal survival and reduce infant mortality.

\section{KEYWORDS}

Umbilical Cord, Single Umbilical Artery, Congenital Anomalies, Infant Mortality.

HOW TO CITE THIS ARTICLE: Sreekumar R, Krishnan S. Prevalence of single umbilical artery and associated congenital anomalies - a foetal study. J. Evolution Med. Dent. Sci. 2017;6(5):402-407, DOI: 10.14260/Jemds/2017/90

\begin{abstract}
BACKGROUND
Umbilical cord is the 'Life-Line' between the foetus and the placenta. It is formed by the $5^{\text {th }}$ week of intrauterine development and it functions throughout pregnancy to protect the vessels that travel between the foetus and the placenta. Compromise of the foetal blood flow through the umbilical cord vessels can have serious deleterious effects on the health of the foetus and newborn. ${ }^{1}$ Cross-section of normal umbilical cord contains two arteries and one vein which are embedded within a spongy, proteoglycan rich matrix known as Wharton's jelly.

Congenital anomalies are the leading cause of infant

major clinical significance. Single minor anomalies present in $14 \%$ of newborn, alert the clinician to the possible presence of an associated major anomaly. The cause of most congenital anomalies $(40 \%-60 \%)$ is unknown. Most common cause is multifactorial, i.e. result from a complex interaction between genetic and environmental factors $(20 \%){ }^{2}$

Many obstetrically important umbilical cord lesions can be diagnosed prenatally and foetal survival can be improved with better prenatal surveillance and timely intervention. Detailed examination of the umbilical cord after birth is an absolute necessity, because of the strong association between umbilical cord anomalies and adverse perinatal outcomes. ${ }^{3}$
\end{abstract} mortality rate accounting for approximately $21 \%$ of infant deaths. ${ }^{2}$ They are also the fifth leading cause of years of loss of potential life prior to age 65 and a major contributor to disabilities. They may be single or multiple and of minor or

Financial or Other, Competing Interest: None.

Submission 23-11-2016, Peer Review 04-01-2017,

Acceptance 10-01-2017, Published 16-01-2017.

Corresponding Author:

Dr. Sreekumar $R$,

Flat No. 615, Block 4,

EMS Nagar, Pattoor, Vanchiyoor P.O.

Trivandrum-695035, Kerala.

E-mail:drsreekumarrs@gmail.com

DOI: $10.14260 /$ jemds $/ 2017 / 90$

\section{(c) $(1) \ominus$}

\section{Objectives}

The present study is a combined work of examining the umbilical cord vasculature and gross anatomy of dead foetuses and to find out the following gross and morphologic parameters: morphological changes in the umbilical cord vasculature, commonly observed congenital malformations seen, prevalence of Single Umbilical Artery/SUA and the pattern of congenital anomalies seen associated with SUA.

\section{MATERIALS AND METHODS}

A total of 110 foetuses from the Department of Pathology, Medical College, Thiruvananthapuram for autopsy were considered for this study. Each autopsy was done only after getting the wilful signature of the informed consent by the 
mother of the dead foetus, after explaining the benefits and risks of this study. Foetuses showing evidence of life-like breathing, heartbeat, pulsation of umbilical cord at the time of delivery were not considered for this study. Foetuses of mothers with chronic hypertension, diabetes mellitus, chronic nephritis, TORCH infections and taking teratogenic drugs like anti-cancer drugs, warfarin, phenytoin, phenobarbitone and isotretinoin also were excluded from this study.

For statistical purposes, foetal deaths were classified into 3 categories according to the gestational age. Early foetal death that occurred at less than 20 weeks of gestation, intermediate foetal death at 20 - 27 weeks of gestation and late foetal death at greater than 28 weeks of gestation. Study incorporated procedures conducted during and after the foetal autopsy. The foetuses were numbered for identification and all the findings were entered in a master chart, which also included the age and sex of the foetus. The findings were assessed under the following headings.

\section{Gross and Morphologic Parameters}

During the foetal autopsy, different parameters were measured. These included crown-rump length, bi-parietal diameter, abdominal circumference, femur length, head circumference, crown-heel length and foot length. The age of the foetus (in weeks) was assessed using the calculation;

Age of foetus (in weeks) = Crown-heel length in inches $\mathrm{x} 2$.

Sex of the foetus was also noted.

The foetus and the placenta were weighed separately. These were weighed three times and the average of these three independent observations was recorded.

\section{Congenital Anomalies}

During the autopsy, the gross structural anomalies in the musculoskeletal system, urogenital system, cardiovascular system, gastrointestinal system, central nervous system and other anomalies were recorded.

\section{Single Umbilical Artery}

Umbilical cord tissue was collected from each case and immediately transferred to $10 \%$ formalin for fixation. The fixed tissue bits were then subjected to routine histological processing. 4 The blocks thus obtained were sectioned at 0.5 micron. The slides were numbered and the key to these numbers contained the age and sex of the foetus from whom the specimens were taken. Sections are carefully transferred to the surface of water bath using paint brush. Then collect the sections on a clean glass slide. Haematoxylin and Eosin staining method is used to study the tissue. The slides thus prepared were examined under light microscopy and the number of vessels noted.

Single Umbilical Artery and Associated Congenital Anomalies

The section of the umbilical cords were studied in detail and the SUA when confirmed were entered in the master chart and its associated anomaly noted.

\section{RESULTS}

The present study evaluated the gross morphologic parameters, congenital anomalies, SUA and SUA associated congenital anomalies. The study was based on the data collected from 110 foetal autopsies.

\section{Gross Morphologic Parameters}

The findings with respect to the various parameters of the 110 foetuses were entered and the mean and the standard error of mean calculated. The descriptive statistics of different parameters is given in Table 1 .

\begin{tabular}{|c|c|c|}
\hline Parameter & N (No. of Cases) & Mean \pm SEM \\
\hline Age of Foetus (Weeks) & 110 & $23.52 \pm 0.70$ \\
\hline Weight of Foetus (Grams) & 110 & $671.79 \pm 65.13$ \\
\hline Weight of Placenta (Grams) & 110 & $385.79 \pm 45.08$ \\
\hline \begin{tabular}{|l|} 
Crown Rump Length (cm) \\
\end{tabular} & 110 & $19.47 \pm 0.65$ \\
\hline Head Circumference $(\mathrm{cm})$ & 110 & $21.06 \pm 0.66$ \\
\hline Crown Heel Length (cm) & 110 & $29.46 \pm 0.90$ \\
\hline Foot Length $(\mathrm{cm})$ & 110 & $4.10 \pm 0.15$ \\
\hline \multicolumn{3}{|c|}{ Table I. Descriptive Statistics } \\
\hline
\end{tabular}

The mean age of the foetuses studied was 23.52 weeks (SD of 7.29). The minimum age was 10 weeks and the maximum age found was 40 weeks. These data were analysed to check whether there is any significant difference in the abovementioned parameters between the foetuses with SUA and others.

Table II shows the distribution and significance of these parameters with reference to the umbilical artery status.

\begin{tabular}{|c|c|c|c|}
\hline \multirow[b]{2}{*}{ Parameter } & \multicolumn{2}{|c|}{ Mean \pm SEM } & \multirow[b]{2}{*}{ P value } \\
\hline & \begin{tabular}{|c|} 
Single \\
Umbilical \\
Artery Cases \\
$(\mathrm{N}=6)$ \\
\end{tabular} & $\begin{array}{c}\text { Normal } \\
\text { Umbilical } \\
\text { Artery Cases } \\
(\mathrm{N}=104)\end{array}$ & \\
\hline Age (Weeks) & $19.50 \pm 1.20$ & $23.75 \pm 0.73$ & 0.014 \\
\hline $\begin{array}{c}\text { Weight of } \\
\text { Foetus (Grams) }\end{array}$ & $279.73 \pm 76.0$ & $694.41 \pm 68.1$ & 0.001 \\
\hline $\begin{array}{c}\text { Weight of } \\
\text { Placenta (Grams) }\end{array}$ & $301.17 \pm 99.73$ & $390.67 \pm 47.36$ & NS \\
\hline $\begin{array}{l}\text { Crown Rump } \\
\text { Length }(\mathrm{cm})\end{array}$ & $17.27 \pm 1.44$ & $19.60 \pm 0.68$ & NS \\
\hline $\begin{array}{c}\text { Head } \\
\text { Circumference }(\mathrm{cm})\end{array}$ & $19.70 \pm 1.22$ & $21.14 \pm 0.69$ & NS \\
\hline $\begin{array}{l}\text { Crown Heel } \\
\text { Length }(\mathrm{cm})\end{array}$ & $24.22 \pm 1.27$ & $29.76 \pm 0.95$ & 0.004 \\
\hline Foot Length $(\mathrm{cm})$ & $3.33 \pm 0.39$ & $4.14 \pm 0.16$ & NS \\
\hline \multicolumn{4}{|c|}{ NS: Not significant } \\
\hline \multicolumn{4}{|c|}{$\begin{array}{c}\text { Table II. Distribution of Parameters } \\
\text { Based on Umbilical Artery Status }\end{array}$} \\
\hline
\end{tabular}

Compared to foetuses with single umbilical artery status, the age, weight and crown heel length were more, for foetuses with normal umbilical artery status. With regards to age, foetal weight and crown heel length ( $\mathrm{p}<0.05)$, there is a statistically significant difference between the foetuses with normal umbilical cord status and single umbilical artery. This states that foetuses with normal number of vessels in the umbilical cord survive and grow better than those with single umbilical artery.

\section{Congenital Anomalies}

The occurrence of congenital malformations was noted during the foetal autopsy. There were $48.18 \%(\mathrm{~N}=53)$ congenital anomalies. Of these $47.17 \%(\mathrm{~N}=25)$ were with multiple congenital anomalies and $52.83 \%(\mathrm{~N}=28)$ with single anomaly. A detailed description is given in Table III. 


\begin{tabular}{|c|c|c|}
\hline System & No. (N) & Percentage (\%) \\
\hline \multicolumn{3}{|c|}{ Musculoskeletal System } \\
\hline Club Foot & 10 & 9.09 \\
\hline Vertebral Anomalies & 5 & 4.55 \\
\hline Cleft Lip & 4 & 3.64 \\
\hline Cleft Palate & 3 & 2.73 \\
\hline Syndactyly & 3 & 2.73 \\
\hline Sirenomelia & 1 & 0.91 \\
\hline \multicolumn{3}{|c|}{ Cardiovascular System } \\
\hline ASD & 2 & 1.82 \\
\hline VSD & 1 & 0.91 \\
\hline \multicolumn{3}{|c|}{ Gastrointestinal System } \\
\hline Omphalocoele & 8 & 7.27 \\
\hline Oesophageal Stenosis & 1 & 0.91 \\
\hline Imperforate Anus & 1 & 0.91 \\
\hline \multicolumn{3}{|c|}{ Central Nervous System } \\
\hline Anencephaly & 6 & 5.45 \\
\hline Meningomyelocele & 4 & 3.64 \\
\hline Hydrocephalus & 4 & 3.64 \\
\hline Holoprosencephaly & 1 & 0.91 \\
\hline Microcephaly & 1 & 0.91 \\
\hline \multicolumn{3}{|c|}{ Others } \\
\hline Cystic Hygroma & 9 & 8.18 \\
\hline Single Umbilical Artery & 6 & 5.45 \\
\hline Pulmonary Hypoplasia & 5 & 4.55 \\
\hline Webbed Neck & 4 & 3.64 \\
\hline Hydrops Foetalis & 4 & 3.64 \\
\hline Diaphragmatic Hernia & 2 & 1.82 \\
\hline Pulmonary Aplasia & 1 & 0.91 \\
\hline \multicolumn{3}{|c|}{$\begin{array}{c}\text { Table III. Distribution of Congenital } \\
\text { Anomalies in the Study Group }(N=110)\end{array}$} \\
\hline
\end{tabular}

The most commonly found anomaly is club foot, $9.09 \%$ (N $=10)$. This was followed by cystic hygroma in $8.18 \%$ cases $(\mathrm{N}$ =9) and omphalocoele in $7 \cdot 27 \%(\mathrm{~N}=8)$.

\section{Musculoskeletal System}

There were 10 club foot cases $(9.09 \%)$. Bilateral club foot was observed in a 27-week-old male foetus (Figure IA).

There were five vertebral anomaly cases (4.55\%). In vertebral anomalies, spina bifida associated with meningocoele was observed (Figure IB).

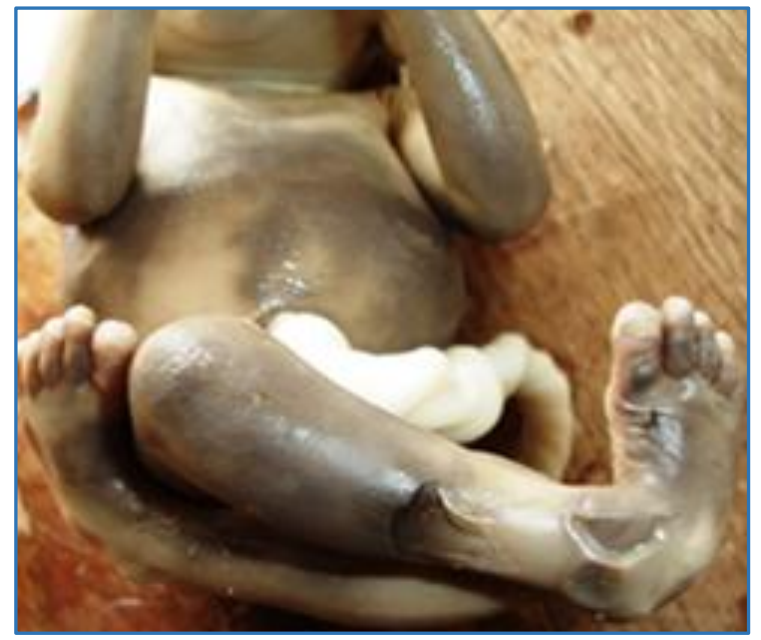

Figure IA. Bilateral Club Foot

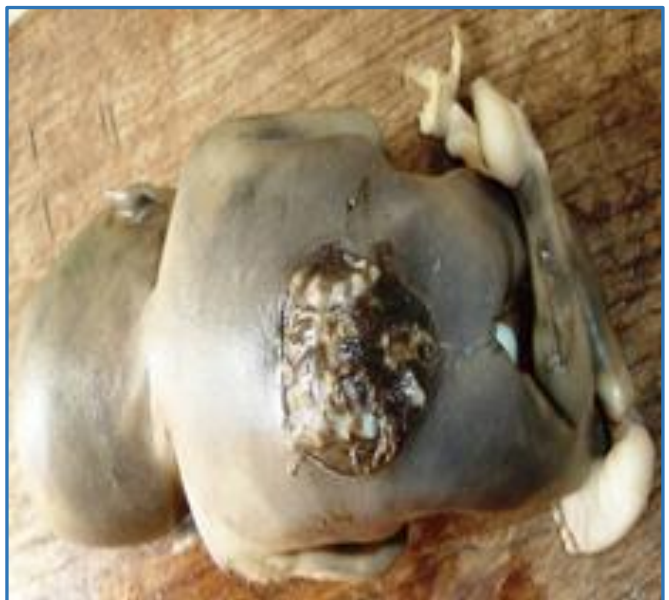

Figure IB. Meningocoele

Four cleft lip (3.64\%) in Fig. IIA and 3 cleft palate cases $(2.73 \%)$ were also noted. There were 3 syndactyly cases $(2.73 \%)$ Fig. IIB shows syndactyly between third and fourth fingers.

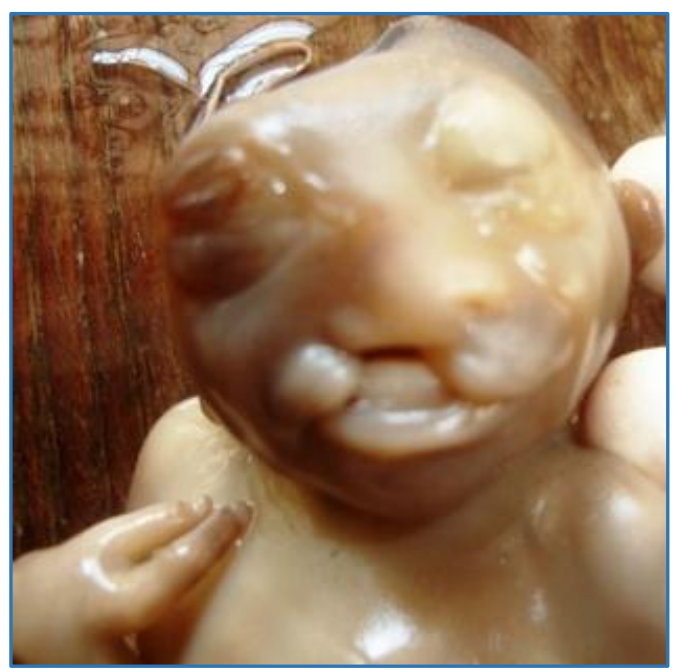

Figure IIA. Upper Right Lateral Cleft Lip

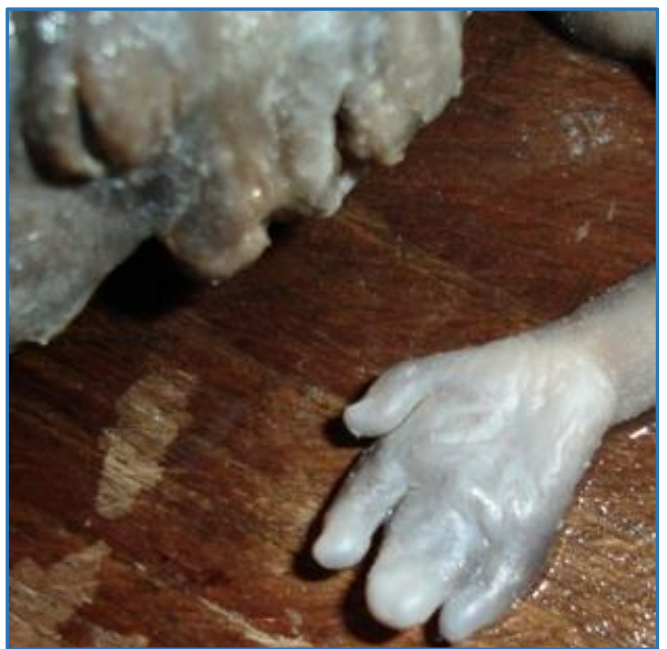

Figure IIB. Syndactyly

There was one sirenomelia case $(0.91 \%)$. This was noted in a 20-week-old male foetus (Fig. IIIA). Upper limbs were normal and the lower limbs were fused. Only one toe was present in the right foot and no toes were present in the left 
foot. Anal opening was absent. Urinary system was not formed. The umbilical cord was examined and it was associated with single umbilical artery (Fig. IIIB).

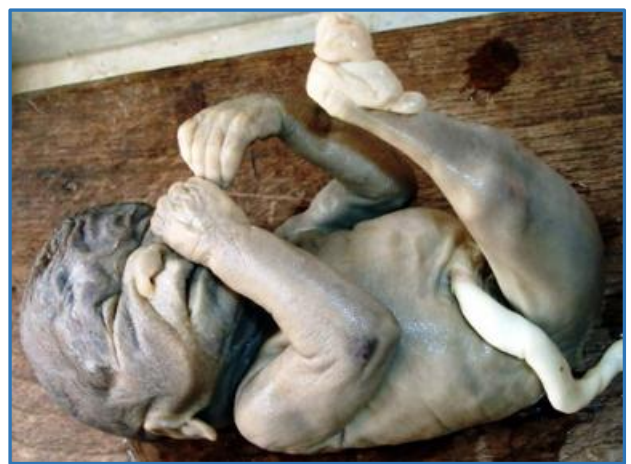

Figure IIIA. Sirenomelia

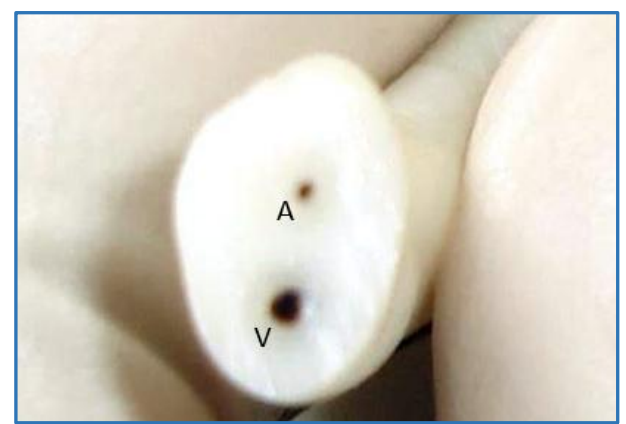

Figure IIIB. Single Umbilical Artery

\section{Urogenital System Anomalies}

There were 6 malformed external genitalia cases (5.45\%) and 4 cases of hydronephrosis (3.64\%). There were 3 cases of renal agenesis and mullerian duct agenesis $(2.73 \%)$. There was one case each of renal hypoplasia and horseshoe kidneys (0.91\%).

\section{Cardiovascular System}

There were 2 cases $(1.82 \%)$ of ASD and one case $(0.91 \%)$ of VSD.

\section{Gastrointestinal System}

There were 8 cases (7.27\%) of omphalocoele and one case each of oesophageal stenosis and imperforate anus $(0.91 \%)$. Fig. IV shows omphalocoele in a 34 weeks foetus.

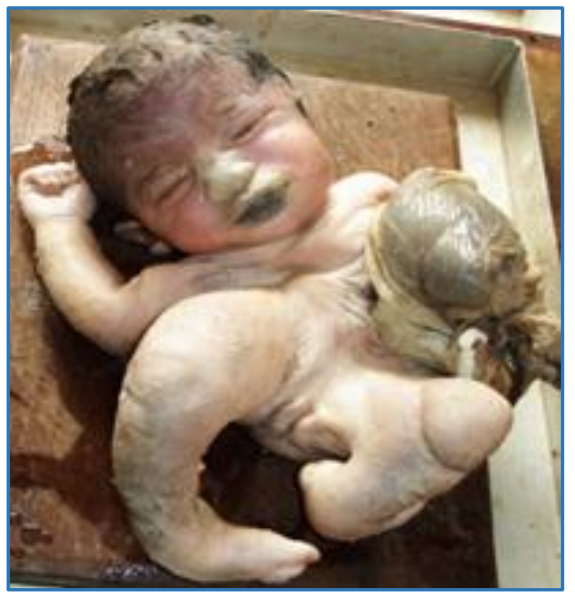

Figure IV. Omphalocoele in a 34 Weeks Old Foetus

\section{Central Nervous System}

There were 6 cases of anencephaly (5.45\%). An anencephalic foetus of 16 weeks gestation is shown in Figure V. There were 4 cases each of meningomyelocele and hydrocephalus (3.64\%). One case each of holoprosencephaly and microcephaly $(0.91 \%)$ was also present.

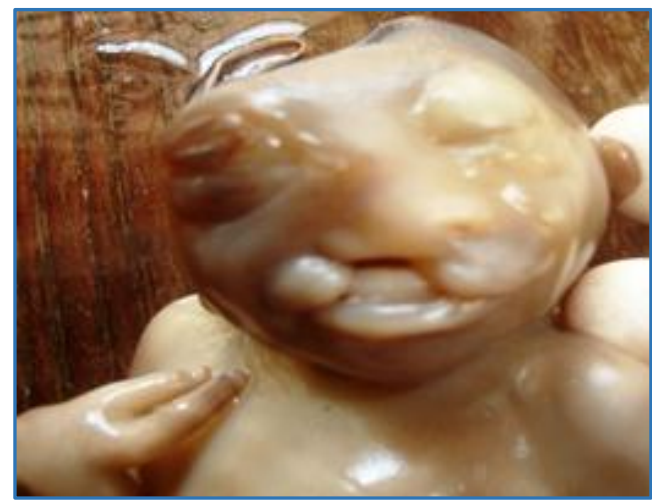

Figure V. Anencephaly

\section{Others}

9 cases of cystic hygroma (8.18\%) are noted. A 19-week-old male foetus with cystic hygroma is shown in Figure Vi; 13.5 cases of pulmonary hypoplasia were noted (4.55\%); 4 cases each of webbed neck and hydrops foetalis (3.64\%) were noted; 2 cases of diaphragmatic hernia (1.82\%) and one case of pulmonary aplasia $(0.91 \%)$ are noted.

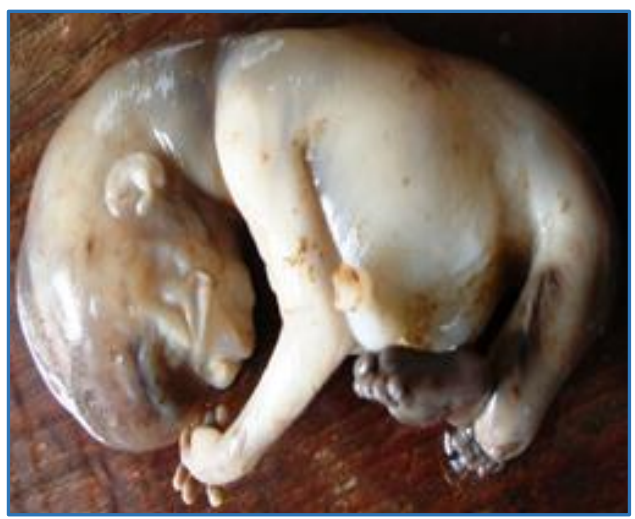

Figure VI. Cystic Hygroma

Single Umbilical Artery and associated Congenital Anomalies

There were 6 cases of single umbilical artery (5.45\%). Crosssection of an umbilical cord showing SUA is shown in the Figure VIIA and its histological picture in Figure VIIB.

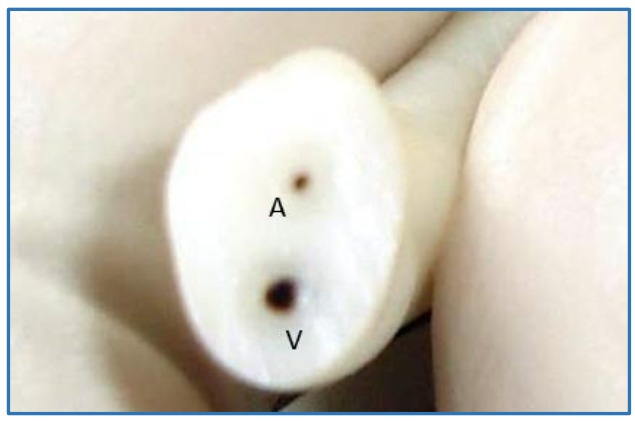

Figure VIIA. Cross-Section of UC showing SUA 


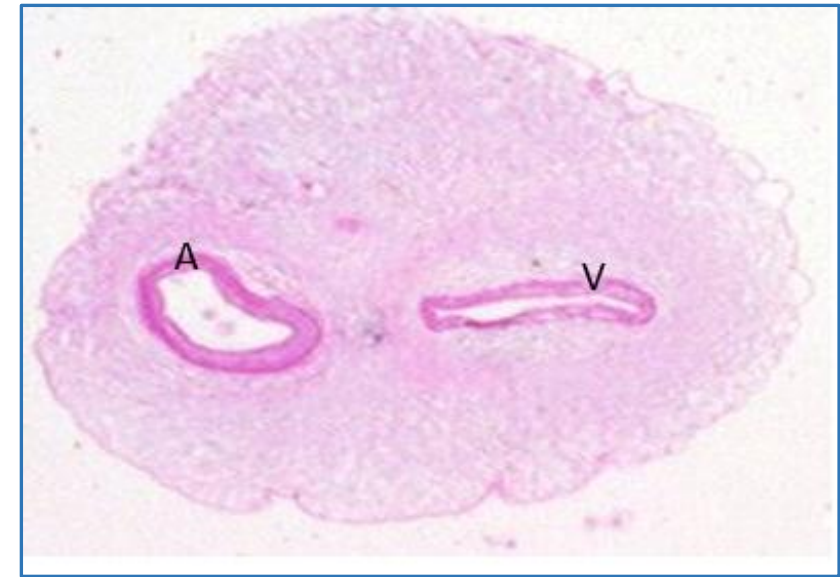

Figure VIIB. Section of Umbilical Cord, Hx and E Stain showing Single Artery (A) and One Vein (V)

In cases with single umbilical artery, the distribution of congenital anomalies was analysed. Of the six single umbilical arteries four are associated with congenital anomalies (66.67\%). The detailed description of the types of congenital anomalies is seen in foetuses with SUA as given below in Table IV.

\begin{tabular}{|c|c|c|}
\hline System & No. (N) & Percentage (\%) \\
\hline \multicolumn{3}{|c|}{ Musculoskeletal System } \\
\hline Vertebral anomalies & 3 & 50.00 \\
\hline Club foot & 1 & 16.67 \\
\hline Sirenomelia & 1 & 16.67 \\
\hline \multicolumn{3}{|c|}{ Gastrointestinal System } \\
\hline Omphalocoele & 1 & 16.67 \\
\hline \multicolumn{3}{|c|}{ Central Nervous System } \\
\hline Meningomyelocele & 2 & 33.33 \\
\hline \multicolumn{3}{|c|}{ Others } \\
\hline Webbed neck & 2 & 33.33 \\
\hline \multicolumn{3}{|c|}{$\begin{array}{c}\text { Table IV. Distribution of Congenital } \\
\text { Anomalies in Foetuses with } S U A(N=6)\end{array}$} \\
\hline
\end{tabular}

Of the six SUA cases, there were ten associated different congenital anomalies. Vertebral anomalies were the most common followed by meningomyelocele and webbed neck. This was followed by meningomyelocele and webbed neck.

\section{DISCUSSION}

The present study on the foetuses was based on the following aspects: Gross morphologic parameters and their association with SUA, various congenital anomalies observed, prevalence of SUA and the relation between congenital anomalies with SUA.

\section{Gross Morphologic Parameters}

Compared to foetuses with single umbilical artery status the age, weight and crown heel length were more, for foetuses with normal umbilical artery status. So foetuses with normal number of vessels in the umbilical cord survive and grow better than those with single umbilical artery. Meiling Hua ${ }^{5}$ found out an increased risk of IUGR associated with presence of SUA. They also reported an increased antepartum stillbirth in foetuses with SUA, which means a reduced age compared with normal vessels.

\section{Congenital Anomalies Observed}

A variety of congenital malformations of various systems were noted. They included anomalies of musculoskeletal system, urogenital system, cardiovascular system, gastrointestinal system, central nervous system and others. Toshio Fujikura ${ }^{6}$ observed $71 \%$ of malformed infants had multiple congenital malformations.

\section{Musculoskeletal System}

In this study musculoskeletal anomalies are having a higher incidence (50\%) in accordance with the study of Luz A. Froehlich $^{7}$ and Mohamed ${ }^{8}$ has stated a higher incidence of musculoskeletal system than CNS.

\section{Urogenital System}

In this, malformed external genitalia was the most common anomaly followed by hydronephrosis. Luz A. Froehlich ${ }^{7}$ found that in Genitourinary system, polycystic kidney and renal aplasia are the most common anomalies seen.

\section{Cardiovascular System}

Atrial septal defect and ventricular septal defect were the common anomalies observed in this study in accordance with the study of Rizk Francine. 9

\section{Central Nervous System}

The most common anomaly was anencephaly followed by meningomyelocele. Luz A Froehlich ${ }^{7}$ had reported that in central nervous system anomalies anencephaly microcephaly and hydrocephaly are seen. But in the present study, anencephaly showed a high prevalence and microcephaly showed a decreased prevalence. Kanan Shah ${ }^{10}$ also found out CNS anomalies were the highest followed by musculoskeletal system. Swain ${ }^{11}$ also stated a higher incidence of CNS anomalies.

\section{Gastrointestinal System}

Omphalocoele was the most common anomaly followed by oesophageal stenosis and imperforate anus. Luz. A. Froehlich ${ }^{7}$ found that in gastrointestinal system, omphalocoele pyloric stenosis and diaphragmatic hernia are seen.

\section{Others}

There were cases of cystic hygroma followed by single umbilical artery pulmonary hypoplasia, webbed neck, hydrops foetalis, diaphragmatic hernia and pulmonary aplasia in this study. Luz A. Froehlich 7 found that in the respiratory system, hypoplasia of lung and diaphragmatic hernia were also seen. Smith ${ }^{12}$ reported sirenomelia was frequently associated with SUA.

\section{Prevalence of SUA}

There were six SUA cases, which constituted a prevalence of $5.45 \%$ of the total 110 cases. The studies of Lorena Mesquita ${ }^{13}$ described a 2\%, Meiling $\mathrm{Hua}^{5}$ a $0.61 \%$, Fatemeh Ghatresamanl $^{14}$ a $1.1 \%$ and Cristina Martinez-Payo ${ }^{15}$ an incidence of $0.7 \%$ by prenatal ultrasound diagnosis. Kristoffersion ${ }^{16}$ stated that the incidence of SUA based on autopsies varies between 2.7 - 12\%. The present study on autopsied foetuses showed an incidence within this range.

Relation between Congenital Anomalies and SUA 
Of the six single umbilical arteries, four were associated with congenital anomalies (66.67\%) and these anomalies were present in the musculoskeletal system, gastrointestinal system, central nervous system and in others. Toshio Fujikura ${ }^{6}$ observed that frequency of congenital malformations associated with SUA was $18.4 \%$. Gastrointestinal and skeletal malformations were more frequent than lesions of the CNS; $71 \%$ of malformed infants had multiple congenital malformations. Kristofferson ${ }^{16}$ reported $15 \%$ - 48\% and even greater, 49.1 - 93\%, in autopsied material. According to Heifetz, ${ }^{17}$ a variety of malformations have been associated with SUA including CVS malformations, CNS defects, GIT defects, musculoskeletal and urogenital defects. Benirschke and Brown ${ }^{18}$ found out an incidence of $1 \%$ SUA with $46 \%$ malformed infants and Fred A. Lyon ${ }^{19}$ observed the foetal anomalies associated with SUA like hydrocephalus, ArnoldChiari malformation, spina bifida with myelomeningocoele, hypoplastic lungs, polycystic horseshoe kidneys, CTEV and anencephaly. According to Heifetz,17 a variety of malformations have been associated with SUA including CVS malformations, CNS defects, GIT defects, musculoskeletal and urogenital defects. Benirschke and Brown ${ }^{18}$ reported that $76 \%$ of malformed infants had multiple congenital malformations.

\section{CONCLUSION}

The present work combined both gross anatomical and associated congenital anomalies with particular reference to the SUA. The overall congenital malformation prevalence obtained in the study was $48.18 \%$ and of these $47.17 \%$ were with multiple congenital anomalies and $52.83 \%$ with single anomaly. Musculoskeletal system anomalies were the most common followed by gastrointestinal and central nervous system anomalies. There were six SUA cases, which constituted a prevalence of $5.45 \%$. Of the six single umbilical arteries, four were associated with congenital anomalies (66.67\%).

Since many obstetrically important congenital anomalies can be diagnosed prenatally, awareness and detection of these conditions antenatally have the potential to improve foetal survival. So the present study will be helpful in gaining some knowledge regarding prevalence of SUA and its association with various congenital anomalies.

\section{REFERENCES}

[1] Kliman HJ. The umbilical cord (from the encyclopedia of reproduction). Yale University School of Medicine 2006;3.

[2] Langman, Sadler TW. Langman's medical embryology. Third Indian Reprint. Chapter 8. Wolters Kluwer (India) Pvt. Ltd. 2011;8(1):113.

[3] Tantibirojn P, Saleemuddin A, Sirois K, et al. Gross abnormalities of the umbilical cord: related placental histology and clinical significance. Placenta 2009;30(12):1083-8.
[4] Slaoui M, Fiette L. Histopathology procedures: from tissue sampling to histopathological evaluation. Methods Molecular Biology 2011;691:69-82.

[5] Hua M, Odibo AO, Macones GA, et al. Single umbilical artery and its associated findings. J Obstetrics \& Gynecology 2010;115(5):930-4.

[6] Fujikura T. Single umbilical artery and congenital malformations. Am J Obstet \& Gynec 1964;88(6):82930 .

[7] Froehlich LA, Fujikura T. Significance of a single umbilical artery. Report from the collaborative study of cerebral palsy. Am J Obstet \& Gynec 1966;94(2):274-9.

[8] El Koumi MA, Al Banna EA, Lebda I. Pattern of congenital anomalies in newborn: a hospital-based study. Paediatric Reports 2013;5(1):e5.

[9] Francine R, Pascale S, Aline H. Congenital anomalies: prevalence and risk factors. Universal Journal of Public Health 2014;2(2):58-63.

[10] Shah K, Pensi CA. Study of incidence of congenital anomalies in new borns. Gujarat Medical Journal 2013;68(2):97-9.

[11] Swain S, Agrawal A, Bhatia BD. Congenital malformations at birth. Indian Pediatrics 1994;31(10):1187-91.

[12] Smith DW. Recognisable patterns of human malformations. Saunders. London. Major problems in clinical paediatrics series 1982;vol VII.

[13] Caldas LM, Liao A, Carvalho MH, et al. Should fetal growth be a matter of concern in isolated single umbilical artery? J Rev Assoc Med Bras 2014;60(2):125-30.

[14] Ghatresamanl F, Javadrashld R, Tarzamnl MK, et al. Single umbilical artrty: prevalence and clinical significance in prenatal ultrasonography. Indian J Radiol Imaging 2007;17(4):269-72.

[15] Martínez-Payo C, Gaitero A, Tamarit I, et al. Perinatal results following the prenatal ultrasound diagnosis of single umbilical artery. Acta Obstet Gynecol Scand 2005;84(11):1068-74.

[16] Kristoffersen K. The significance of absence of one umbilical artery. Acta Obstet Gynec Scandinav 1969;48(2):195-214.

[17] Heifetz SA. Single umbilical artery. A statistical analysis of 237 autopsy cases and review of the literature. Perspect Ped Path 1984;8(4):345-78.

[18] Benirschke K, Bourne GL. The incidence and prognostic implication of congenital absence of one umbilical artery. Am J Obstet \& Gynec 1960;79:251-4.

[19] Lyon FA. Fetal abnormalities associated with umbilical cords containing one umbilical artery and one umbilical vein. Obstetrics \& Gynecology 1960;16:719-21. 